\title{
Estimating the contribution of rainfall, irrigation and upward soil water flux to crop water requirements of a maize agroecosystem in the Lombardy plain
}

\author{
Michele Rienzner, Sandra Cesari de Maria, Arianna Facchi, Fatma Wassar, Claudio Gandolfi \\ Department of Agricultural and Environmental Sciences (DiSAA), Università degli Studi di Milano, \\ Italy
}

\section{Introduction}

The unsaturated zone plays an important role in the hydrological cycle, since it is at the interface between atmosphere and groundwater circulation. Water fluxes in the unsaturated zone affect water status, development and production of crops; by an environmental point of view, these fluxes determine mobilization and transport of solutes and pollutants from the soil surface to the aquifer system.

There are several reasons for modelling hydrological processes in the unsaturated zone, one of them is definitely the existing limit at the possibility of measuring all the variables we need to know about the physical system. The models are used to perform extrapolations or predictions that, reasonably, are expected to be useful in decision-making processes focused on hydrological issues (Beven, 2001).

Water movements in the unsaturated zone can be described with mathematical formulations based on different approaches (e.g. Gandolfi et al., 2006) going from very simplified conceptual schemes to models, as SWAP (Kroes and van Dam, 2003), Hydrus-1D (Šim nek et al., 2008), U3M-1D (Vaze et al., 2004), implementing the numerical solution of the Richards' differential equation. The latter set of models

Correspondence: Michele Rienzner, Dipartimento di Scienze Agrarie e Ambientali (DiSAA), Università degli Studi di Milano, Via Celoria 2, 20133, Milano (MI), Italy.

Tel. +39.02.50316901 - Fax: +39.02.50316911.

E-mail: michele.rienzner@unimi.it

Key words: SWAP, calibration, SCEM-UA, maize water requirements, capillary rise

Acknowledgements: the authors would like to thank Regione Lombardia for funding the AC-CA project, as well as those who took part in for their meaningful contribution. The first author thanks the MIUR as well for financing his research grant.

Contributions: the authors contributed equally.

Conflict of interests: the authors declare no potential conflict of interests.

Funding: MIUR, Regione Lombardia

(C) Copyright et al., 2013

Licensee PAGEPress, Italy

Journal of Agricultural Engineering 2013; XLIV(s2):e18

doi:10.4081/jae.2013.s2.e18

This article is distributed under the terms of the Creative Commons Attribution Noncommercial License (by-nc 3.0) which permits any noncommercial use, distribution, and reproduction in any medium, provided the original author(s) and source are credited. simulate soil, plant and atmosphere as a continuous system in which water movements are driven by potential gradients. In case a thorough analysis of the physical processes is required and all the needed information is available, complex models are usually preferred.

A modelling approach is particularly interesting in sites where there is a strong interaction between the processes occurring at the soil surface and the groundwater, as in areas characterized by shallow groundwater tables. In such situations, a water flow towards the roots zone is triggered by the strong potential gradient that occurs when the soil water content nearby the roots becomes very negative. A model simulation can be very useful in the estimation of this upward flux since a reliable direct measurement is at least a complex task.

Numerous studies, performed by different approaches, attempted to quantify the contribution of the capillary rise to the root zone soil water balance, taking into account several variables including, particularly, the crop type and the groundwater depth. Kahlown et al. (2005) reported that with a groundwater depth of $0.5 \mathrm{~m}$ irrigation of wheat was no longer required, while in the case of sunflower an irrigation supply equal to the $20 \%$ of the evapotranspiration volume showed to be sufficient. Prathapar and Qureshi (1999) showed that with a groundwater depth within $2 \mathrm{~m}$ from the topographic surface, crops were able to extract a considerable fraction of the water they needed. Kahlown $e t$ al. (1998) illustrated how a groundwater depth of $1 \mathrm{~m}$ represents the optimum situation for the growth of many crops, while the capillary rise contribution to the root zone water balance becomes negligible when the groundwater depth becomes 2-3 m. Liu and Luo (2011) suggested a groundwater table at $1.5 \mathrm{~m}$ from the soil surface as the optimum for the winter wheat, since this depth allows its complete root development. Kahlown et al. (2005) suggested the optimal groundwater depth to be between 1 and $2 \mathrm{~m}$ for all the crops they investigated. For the maize crop, the same authors reported a required irrigation contribution of $75 \mathrm{~mm}$ when the groundwater depth was $1 \mathrm{~m}$, this contribution was shown to increase approximately linearly with the increasing of the water table depth (the linear decrease was highlighted for all the crops examined). A linear relationship between the groundwater depth and the required irrigation amount was also detected by other authors, including Sepaskhah et al. (2003). Authors, however, came to different conclusions, since factors such as climate of the experimental areas or soil types therein play a non-negligible role.

Although maize is a crop fairly affected by water ponding (often happening when shallow groundwater combines with heavy rains or abundant irrigation), massive roots uptake and yields are documented also with groundwater depths of few tens of centimetres. With a water table depth of $0.5 \mathrm{~m}$ several authors found groundwater contributions around $40 \%$ of the crop water requirements and an increase in yield (Follett et al., 1974; Cavazza and Pisa, 1988; Pisa and Ventura, 1991). The same contribution was observed by Kahlown et al. (2005) for maize in an arid region of Pakistan. These authors also reported that the contribution decreases to $30 \%$ of the crop water requirements with a groundwater depth of $1 \mathrm{~m}$ and to $7.5 \%$ with a groundwater depth of $1.5 \mathrm{~m}$. Soppe and Ayars (2003) showed that the contribution of shallow 
water tables is not constant in time but increases with the increasing of the rooting depth, reaching its maximum value at the end of the growth phase of the plant, when roots are fully developed. Liu and Luo (2011) concluded their study proposing irrigation systems in which the water table depth could be maintained at a depth of $1.5 \mathrm{~m}$ or less, allowing an increase in crop production and a reduction in the use of surface irrigation.

In order to have a reliable model estimation of the water fluxes, especially in case of complex physically based models (i.e. implementing the Richards' equation), a relevant effort has to be spent for the quantification of the model parameters. Some of the needed parameter values are difficult to be quantified, even in presence of in-field or lab measurements. Among them, the effective soil saturated hydraulic conductivity $\left(K_{s}\right)$, which is the value needed by the model (valid under the hypothesis of spatial homogeneity), is actually a virtual value since it does not correspond to any specific conductivity that can be measured in the field where a relevant spatial variability usually exists. The calibration of $K_{s}$ can be done through inverse modelling (i.e. finding the value of the parameters giving the best fit between field measurements and model outputs) adopting the algorithms available in literature for the global optimum search (e.g. SCE-UA, SCEM-UA, PEST, SWARM).

This research aims at estimating the upward groundwater flux in an experimental case characterized by a shallow groundwater table (as it is typical for large areas of the Po valley plain) in order to assess its contribution to the satisfaction of maize water requirements among the other water inputs (rain and irrigation). For this purpose, the hydrological model SWAP (Soil Water Atmosphere Plant model, Kroes and van Dam, 2003) has been implemented using detailed monitoring data collected in field. For the calibration of the saturated hydraulic conductivity, the model has been coupled with the algorithm SCEM-UA (Vrugt et al., 2003), which is effective and efficient in locating the optimal values in multidimensional parameters spaces in case of highlynon-linear systems. In this paper, preliminary results concerning one site and one year are presented and discussed.

\section{Materials and methods}

\section{Monitoring activity}

In the agricultural seasons 2010 and 2011, an intensive monitoring activity was carried out for quantifying fluxes and storage of water and carbon in two maize agro-ecosystems of the Lombardy plain, according to the purpose of the AC-CA project (Gandolfi et al., 2012), funded under the Lombardy agricultural research program 2007-2009. The experimental site this paper is concerned is a 10 ha field located in Landriano (Figure $1-45^{\circ} 19^{\prime} \mathrm{N}, 9^{\circ} 15^{\prime} \mathrm{E}, 88 \mathrm{~m}$ a.s.l), characterized by a shallow groundwater table depth ( 0.6 to $1.5 \mathrm{~m})$.

In both the years the field was seeded with a long season Zea Mays variety (class 600-700) and a border irrigation was applied just in the first one. The monitoring setup involved an eddy covariance tower measuring water and carbon fluxes and instruments for the continuous monitoring of the soil water status installed in six Intensive Monitoring Plots (IMPs hereafter). Each IMP was provided with: (i) a FDR Sentek soil water content probe (sensors placed at 7, 27, 47, $67 \mathrm{~cm}$ depth), (ii) 4 tensiometers (installed at the same depths of the soil water content sensors) and (iii) a $3 \mathrm{~m}$ piezometric pipe equipped with a STS pressure transducer. Moreover, about 8 campaigns per agricultural season were carried out in each IMP to measure crop biometric parameters (leaf area index, crop height and rooting depth) and to collect soil samples for assessing soil physico-chemical properties (soil texture, organic matter content, bulk density). At the same dates also saturated hydraulic conductivity measurements with two Guelph permeameters and one tension infiltrometer were carried out at the same sites (Rienzner et al., 2011). Finally, undisturbed soil samples were extracted in September 2010 for the laboratory determination of soil retention curves (by tension plates and the Richards' pressure plate apparatus).

\section{The SWAP hydrological model}

Among the numerical models solving the Richards' equation in the one-dimensional vertical form, SWAP (Soil Water Atmosphere Plant model, Kroes and van Dam, 2003) is one of the most widely used and best documented. It adopts the modified differential Richards' equation which includes a sink term representing the macroscopic flow extracted by the vegetation (depending on plant characteristics, local soil water potential and transpiration demand due to climate). SWAP solves the Richards' equation by a finite difference scheme adapted from those described by Haverkamp et al. (1977) and Belmans et al. (1983); initial and bottom boundary conditions must be provided as input.

The soil profile is modelled as a sequence of layers, each one with its own hydraulic characteristics. The layers are further discretized into smaller compartments adopted in the finite differences solution scheme. Soil retention curves $\theta(h)$ and unsaturated hydraulic conductivity $K(\theta)$ of the layers are described by the analytic equations of Van Genuchten (1980) and Mualem (1976) respectively. Regarding the crop development, SWAP includes a detailed crop growth model (WOFOST 6.0, Spitters et al., 1989; Hijmans et al., 1994) and, alternatively, a simple module needing the time series of leaf area index (LAI) or soil cover fraction (CF), crop height, roots depth and distribution. The interception is modelled by the analytical model proposed by Von HoyningenHune (1983) and Braden (1985). The potential evapotranspiration can be calculated either by the Penman-Montieth equation (Allen et al., 1998) or by applying crop factors to a reference evapotranspiration given in input. Then, the actual transpiration is derived from the potential accounting for soil cover, moisture and salinity conditions in the root zone (weighted by the root density), while the actual evaporation depends on the capacity of the soil to transport water to the soil surface. As regards irrigation, it can be fixed or scheduled by SWAP choosing among different time and depth criteria.

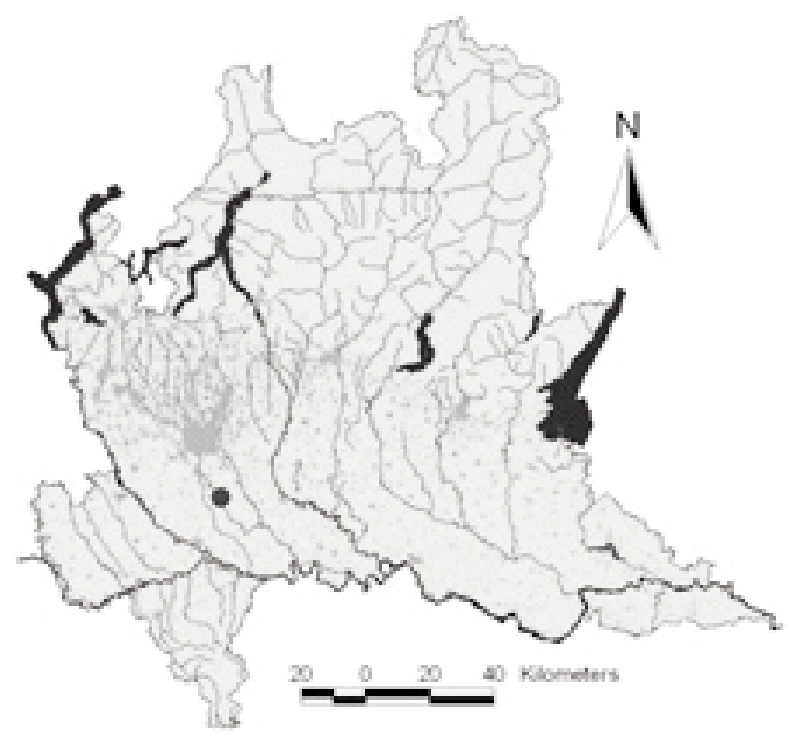

Figure 1. Location of the experimental site (black dot) within the Lombardy region. 


\section{Input data and SWAP parameterization}

Among the collected data (6 IMPs and two years), IMP-5 year 2010 was chosen as case study for this contribution. The chosen simulation period starts on 08/05/2010 (2 days before crop emergence) and ends at the maize harvesting (11/09/2010). The initial conditions of soil water potential were fixed according to the groundwater level measured in the day the simulation starts (1 cm below the soil surface) and the bottom boundary condition was fixed by the daily series of groundwater depth. Soil profile was divided into four layers having their centre at the sensors depth (Section 2.1), further divided in 1 cm-thick compartments; the fourth layer was extended up to the bottom of soil profile $(4 \mathrm{~m})$.

The four retention curves were obtained by least squares regression, on the pairs of water content $(\theta)$ and water potential (h) values measured at the four different depths, with the Van Genucthen curve. The calibration values were the collected field measurements (along the season) and the laboratory test out comes made with tension and Richards' plates apparatus on undisturbed soil samples taken in September 2010 at the same depths of the sensors. Van Genucthen curve calibration was performed by using a MATLAB algorithm solving nonlinear curve-fitting problems in least-squares sense (lsqcurvefit.m of the MATLAB Optimization Toolbox; Coleman and Li, 1996) for all the parameters except of the saturated water content, which was selected according to field measurements.

Maize growth was computed using the simple crop module since the crop biometric measurements were directly collected in field (linear interpolation was used to obtain the complete time series).

Daily meteorological data recorded by a $200 \mathrm{~m}$-far meteorological station were used, i.e. solar radiation $\left(\mathrm{KJ} \mathrm{m}^{-2}\right)$, maximum and minimum temperature $\left({ }^{\circ} \mathrm{C}\right)$, air humidity $(\mathrm{KPa})$, wind speed $\left(\mathrm{m} \mathrm{s}^{-1}\right)$ and rain (mm). As regards irrigation, on day 25/07/2010 a water amount was supplied by border irrigation which produced in IMP-5 an estimated infiltration of $65.9 \mathrm{~mm}$ (obtained assessing local water table fluctuations and changes in soil moisture).

\section{SCEM-UA}

SCEM-UA (Shuffled Complex Evolution Metropolis - usable algorithm (Vrugt et al., 2003a; Vrugt et al., 2003b) is an algorithm for optimization, inverse modeling and assessment of hydrologic model parameters. It provides an estimate of the most likely parameter set and its underlying posterior probability distribution. The algorithm is a Markov Chain Monte Carlo (MCMC) sampler, which generates multiple sequences of parameter sets that converge to the stationary posterior distribution for a large enough number of simulations. For further details of SCEM-UA's functioning the reader should refer to Vrugt et al., 2003a; Vrugt et al., 2003b.

Among the automatic calibration procedures, SCEM-UA has been chosen as it is consistent, effective and efficient in locating the optimal model parameters in multidimensional parameters spaces which may not be smooth. As a matter of fact, the case study performed required a calibration of a highly-non-linear system with a four-dimensional parameters space (saturated hydraulic conductivity at four depths).

A pre-alpha version of SCEM-UA (MATLAB version) was used and coupled with the stand-alone model (SWAP.exe) through a set of MAT$\mathrm{LAB}$ functions and scripts written in order to virtually make SWAP running within the MATLAB environment.

The objective function leading the assessment of the "best" parameter set was defined as a weighted mean of the squared error between measured and simulated values (i.e. soil water potential, soil water content and water table depth). The weight of each term was set according to the reliability of the corresponding measured data. Results of the calibration procedure are described in Section 3.

\section{Results}

In this section are presented both the optimal $K_{s}$ sets given by SCEMUA for the four soil layers the profile was divided in, along with some details of the calibration, and an analysis of the corresponding SWAP outputs.

\section{$K_{s}$ estimation}

A wide range of $K_{s}$ values, going from 0.01 to $1000 \mathrm{~cm} \mathrm{~d}^{-1}$, was given to SCEM-UA as prior distribution of the parameters (actually the inverse problem was performed on decimal log-transformed $K_{s}$ ranging from -2 to 3). After some exploratory SCEM-UA applications (changing e.g. the weights in the objective function), a suitable inverse solution was obtained with a 15,000 simulations run. The main SCEM-UA output is a matrix having in each row the four parameters corresponding to each SWAP run and the resultant value of the objective function. A selection of 100 parameter sets (100-0pt hereafter) was obtained by extracting the rows having the best 100 values of the objective function, the same was done for the 20 best sets (20-0pt hereafter).

Figure 2 shows the four frequency distributions, one for each layer, of 100-0pt (light grey) and 20-0pt (dark grey). The distributions are bell-shaped and their ranges, compared with their mean values, are quite narrow indicating that the optimization, after a thorough investigation of the whole space, converged to a small area corresponding to the optimal solution in the 4D parameter space.

The values of the objective function of 100-0pt, divided by the overall worst value, range from 0.0128 to 0.0132 . As different combinations of the four parameters gave nearly equivalent scores of the objective function, the results of the inverse problem consist of multiple solutions for the saturated hydraulic conductivities of the soil profile. The means of the calibrated $K_{s}(100-0 \mathrm{pt})$, going from the first layer (close to the soil surface) to the fourth one, are $10.96,1.76,3.74$ and $4.79 \mathrm{~cm} \mathrm{~d}^{-1}$ showing some variation along the profile. Notice the conductivity is smaller in the layers containing the plough pan.

A confirm of the SCEM-UA estimation for the shallower layers is
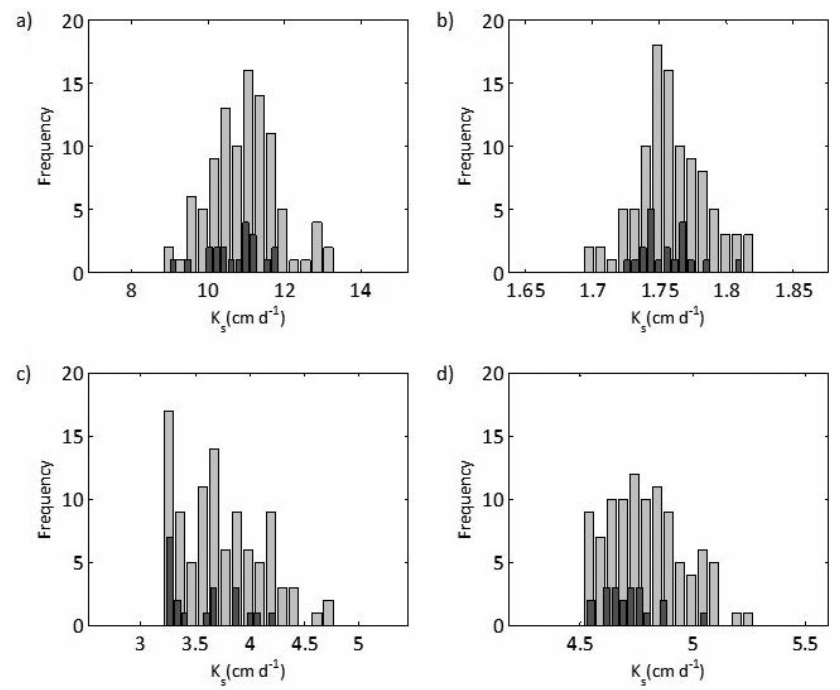

Figure 2. Posterior distribution of the Ks values estimated for the layers: (a) 0-17 cm, (b) $17-37 \mathrm{~cm}$, (c) $37-57 \mathrm{~cm}$, (d) $57-77 \mathrm{~cm}$. 
found in the results of the Guelph permeameter campaigns (Rienzner et al., 2011; Gandolfi et al., 2012) conducted in the same period and IMP. In fact, the measured values of $K_{s}$, involving the first $30 \mathrm{~cm}$, ranged from 2.8 to $9.1 \mathrm{~cm} \mathrm{~d}^{-1}$, in agreement with the calibration results for the first two layers.

\section{SWAP outputs}

The SWAP model was run with the 100-0pt $K_{s}$ set in order to quantify the upward flux. Capillary rises were thus computed on each day of simulation as the upward fluxes pouring out from the model compartment immediately below the root depth (which changes in time according to the field measurements). The 100 total upward fluxes were then replicated proportionally to their objective score (100 replicates for the best simulation and 1 to the $100^{\text {th }}$ ); the histogram of the upward flux is reported in Figure 3.

As an example of the model fitting, Figure 4 shows the measured and simulated soil water contents along the crop season for the 20-0pt $K_{s}$ set. In the figure, the 20 lines cannot be distinguished due to an overlying of the results, confirming the modelling error to be equivalent in the set.

Finally, Table 1 reports the different contribution to the maize water requirements due to rain, irrigation and capillary rise (100-0pt set), and the water percolation computed in the same way of the upward flux.

\section{Conclusions}

In order to compute a complete water balance of a Lombardy maize field, including percolation and capillary rise, the SWAP model was implemented with a complete set of field measurements accounting for meteorology, soil properties, measurable water fluxes and crop features. Nevertheless, a calibration procedure of the saturated soil hydraulic conductivities along a layered profile was needed for a reliable application of the model, since it is rather unrealistic to measure directly the effective values of $K_{s}$ within some square meters and at different depths without disturbing the cropped soil. For this purpose, the MATLAB SCEM-UA toolbox was coupled with the SWAP model in order to obtain an optimal estimation of $K_{s}$ sets able to represent the experimental soil profile.

The preliminary results for IMP-5-year 2010 show that the potential evapotranspiration ( $464 \mathrm{~mm}$ ) is not fulfilled since actual transpiration amounts to $403 \mathrm{~mm}$. It is worth to stress that, while irrigation and rain contribute to the satisfaction of both the soil evaporation and the plant transpiration, the upward flux ( $237 \mathrm{~mm}$ ) contributes mainly to transpiration. Moreover, most of rain and irrigation $(379 \mathrm{~mm})$ percolate (308 $\mathrm{mm}$ ) but, due to the shallow groundwater table, capillary rise compensates almost $80 \%$ of the same percolation losses, greatly increasing the water efficiency of the whole system.

Rain, irrigation and capillary rise account, respectively, for $67 \%, 14 \%$ and $51 \%$ of the crop water requirements represented by the potential evapotranspiration. A significant contribution of capillary rise was thus noticed in case of shallow groundwater which ensured about half the potential evapotranspiration flux; this percentage is even greater than the values found by other authors (i.e. up to $40 \%$ with a water table 50 cm below the soil surface in Follett et al., 1974; Cavazza e Pisa, 1988; Pisa e Ventura, 1991; Kahlown et al., 2005).

Concluding, the adopted approach involving the inverse calibration of a physically based model is a promising tool to enhance the analysis of the soil-water-plant system with particular reference to the interactions between the groundwater and the root zone which significantly influence the whole system.

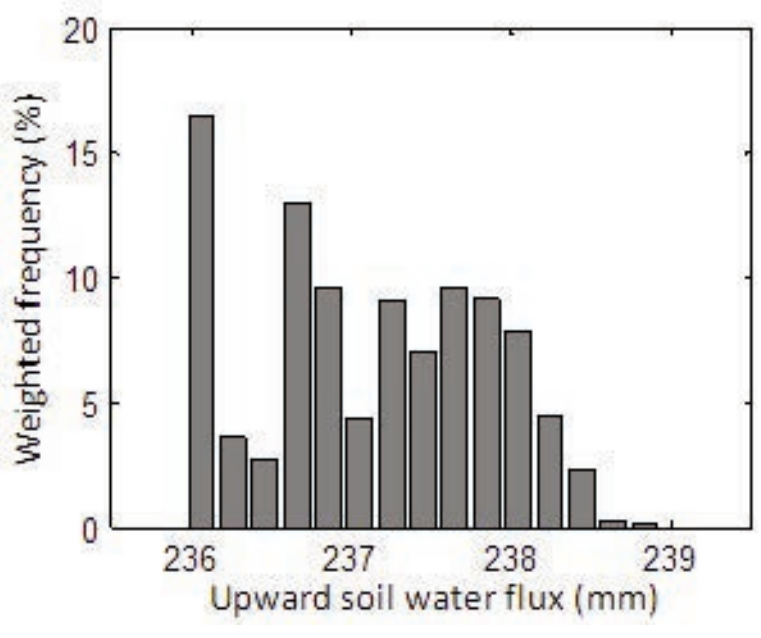

Figure 3. Histogram of the 100-Opt upward flux, weighted in frequency proportionally to the corresponding value of the objective function.

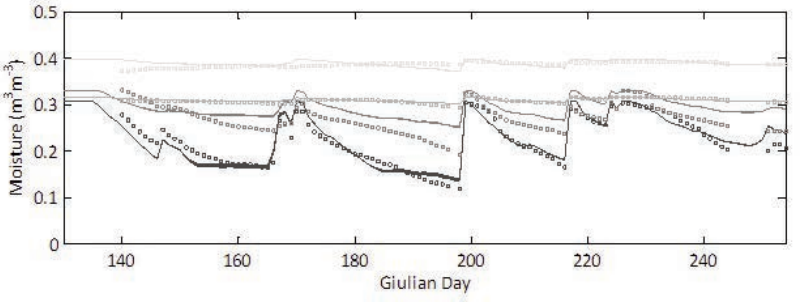

Figure 4. Moisture trends for the four layers: measured data at the sensors depths (squares) and model outputs for the 20-Opt set at the same depths (straight lines); grey getting lighter moving downward the soil profile.

Table 1. Average fluxes as obtained by the 100-Opt SWAP simulations, percentage of satisfaction of the potential evapotranspiration are also provided ( $\mathrm{E}$ and $\mathrm{T}$ are the evaporation and transpiration components)

\begin{tabular}{|c|c|c|c|c|c|c|}
\hline $\begin{array}{l}\text { Potential ET } \\
(\mathrm{mm})\end{array}$ & $\begin{array}{l}\text { Net rain } \\
(\mathrm{mm})\end{array}$ & $\begin{array}{l}\text { Irrigation } \\
(\mathrm{mm})\end{array}$ & $\begin{array}{c}\text { Mean Actual ET } \\
(\mathrm{mm})\end{array}$ & $\begin{array}{l}\text { Mean percolation } \\
(\mathrm{mm})\end{array}$ & $\begin{array}{l}\text { Mean upward flux } \\
(\mathrm{mm})\end{array}$ & \\
\hline $\begin{array}{l}464 \text { (E 293, T 171) } \\
(86 \%)\end{array}$ & $\begin{array}{c}313 \\
(-66 \%)\end{array}$ & $\begin{array}{c}66 \\
(51 \%)\end{array}$ & 403 (E 255, T 148) & -308 & $237(67 \%)$ & $(14 \%)$ \\
\hline
\end{tabular}




\section{References}

Allen, R.G., Pereira, L.S., Raes, D., Smith, M. 1998. Crop evapotranspiration: guidelines for computing crop water requirements, Irrigation and Drainage Paper 56. United Nations FA0, Rome, pp 300.

Belmans C., Wesseling J.G., Feddes R. 1983. Simulation of the water balance of a cropped soil: SWATRE. J Hydrol. 63:271-286.

Beven K. 2001. Rainfall-Runoff Modelling. The Primer.Wiley \& Sons, Ltd.

Braden H. 1985. Ein Energiehaushalts - und Verdunstungsmodell for Wasser und Stoffhaushaltsuntersuchungen landwirtschaftlich genutzer Einzugsgebiete. Mittelungen Deutsche Bodenkundliche Geselschaft. 42:294-299.

Cavazza L., Pisa P.R. 1988. Effect of watertable depth and waterlogging on crop yield. Agr Water Manage. 14:29-34.

Coleman T.F., Li Y. 1996. An Interior, Trust Region Approach for Nonlinear Minimization Subject to Bounds. SIAM J Optimiz. 6:418445.

Follett R.F., Doering E.J., Reichman G.A., Benz L.C. 1974. Effect of irrigation and water-table depth on crop yields. Agron J. 66:304- 308.

Gandolfi C., Facchi A., Gharsallah 0., Wassar F., Rienzner M., Chiaradia E., et al. 2012. Progetto ACCA. Relazione finale: Regione Lombardia. http://www.lavoro.regione.lombardia.it/ shared/ccurl/ 291/119/ACCA_Relazione\%20Finale.pdf

Gandolfi C., Facchi A., Maggi D. 2006. Comparison of 1D models of water flow in unsaturated soils. Environ Modell Softw. 21:17591764.

Haverkamp R., Vauclin M., Touma J., Wierenga P.J., Vachaud G. 1977. A comparison of numerical simulation models for one-dimensional infiltration. Soil Sci Soc Am J. 41:285-294.

Hijmans R.J., Guiking-Lens I.M., van Diepen C.A. 1994. User's guide for the WOFOST 6.0 crop growth simulation model. Technical Document 12, Alterra Green World Research, Wageningen, pp 144.

Kahlown M.A., Ashraf M., Zia-ul-Haq. 2005. Effect of shallow groundwater table on crop water requirements and crop yields. Agr Water Manage. 76:24-35.

Kahlown M.A., Iqbal M., Skogerboe G.V., Rehman 1998. S.U. Water logging, salinity and crop yield relationships. Mona Reclamation Experimental Project, WAPDA. Report No. 233.

Kroes J.G., van Dam J.C. 2003. Reference Manual SWAP version 3.0.3. Alterra-report 773. Wageningen, Alterra, Green World Research. ISSN 1566-7197.

Liu T., Luo Y. 2011. Effects of shallow water tables on the water use and yield of winter wheat (Triticum aestivum L.) under rain-fed condi- tion. Aust J Crop Sci. 5(13):1692-1697.

Mualem Y. 1976. A new model for predicting the hydraulic of unsatured porous media. Water Resour Res. 12:513-522.

Pisa P.R., Ventura F. 1991. Groundwater table contribution to crop water budget: a review. Irrigazione e drenaggio. 38(1): 3-14.

Prathapar S.A., Qureshi A.S. 1999. Modelling the effects of deficit irrigation on soil salinity, depth to water table and transpiration in semi-arid zones with monsoonal rains. Int $\mathrm{J}$ Water Resour D. 15:141-159.

Rienzner M., Garlaschelli F., Gandolfi C. 2011. Analisi statistica della conducibilità idraulica satura stimata in campo per un suolo superficiale. Convegno di Medio Termine dell'Associazione Italiana di Ingegneria Agraria; Belgirate, 22-24 settembre 2011. http:/www.aiia2011.unimi.it/chiave/memorie/2.pdf

Sepaskhah A.R., Kanooni A., Ghasemi M.M. 2003. Estimating water table contributions to corn and sorghum water use. Agr Water Manage. 58:67-79.

Šimůnek J., Šejna M., Saito H., Sakai M., van Genuchten M.Th. 2008. The Hydrus-1D Software Package for Simulating the Movement of Water, Heat, and Multiple Solutes in Variably Saturated Media, Version 4.0. HYDRUS Software Series 3. Department of Environmental Sciences, University of California Riverside, Riverside, California, USA, pp 315.

Soppe R.W.O., Ayars J.E. 2003. Characterizing ground water use by safflower using lysimeters. Agr Water Manage. 60:59-71.

Spitters C.J.T., van Keulen H., van Kraalingen D.W.G. 1989. A simple and universal crop growth simulator: SUCROS87. In: Rabbinge R, Ward SA, van Laar HH (Eds.) Simulation and systems management in crop protection, Simulation Monographs, Pudoc.

Van Genuchten M.Th. 1980. A closed form equation for predicting the hydraulic conductivity of unsatured soils. Soil Sci Soc Am J. 44:892898.

Vaze J., Tuteja N.K., Teng J. 2004. CLASS Unsaturated Moisture Movement Model U3M-1D. User's Manual. NSW Department of Infrastructure, Planning and Natural Resources, Australia and Cooperative Research Centre for Catchment Hydrology, Australia. ISBN 0734755139.

Von Hoyningen-Hüne J. 1983. Die Interception des Niederschlags in landwirtschaftlichen Beständen. Schriftenreihe des DVWK. 57:153.

Vrugt J.A., Gupta H.V., Bouten W., Sorooshian S.A. 2003a. A Shuffled Complex Evolution Metropolis algorithm for optimization and uncertainty assessment of hydrologic model parameters. Water Resour Res. 39(8), 1201.

Vrugt, J.A., Gupta H.V., Bastidas L., Bouten W., Sorooshian S. 2003b. Effective and efficient algorithm for multi-objective optimization of hydrologic models. Water Resour Res. 39:1214. 